\title{
EDUCATION
}

\section{A cohort investigation of the changes in vocational dental practitioners' views on repairing defective direct composite restorations}

\author{
I. R. Blum, ${ }^{1}$ J. T. Newton ${ }^{2}$ and N. H. F. Wilson ${ }^{3}$
}

\section{"When newly qualified dentists enter general dental practice, typically to undertake $V T$, they may be confronted with many dilemmas"}

Objective: To investigate changes in vocational dental practitioners (VDPs) views on repairing direct composite restorations (DCRs) during the vocational training (VT) year 2002-2003.

Design: A questionnaire-based cohort study.

Method: Data on the repair of DCRs, including indications and details of operative techniques were collected by a questionnaire sent at the beginning of the VT year (September 2002) to all 12 Postgraduate Dental Deans in England. A follow-up questionnaire was sent to the Deans near the end of the VT year (May 2003). They were asked, on both occasions, to distribute the questionnaires among their VDPs and to return the completed questionnaires.

Results: Ten deaneries participated in the study. The September 2002 and May 2003 findings (306 respondents [66\%] and 313 respondents [67\%] respectively) were analysed using Chi-square statistic and t-test to identify any significant differences $(P<0.05)$. Significant changes in the attitudes of the VDPs during the VT year included a shift to viewing reduction in treatment time (30\% to 48\%), cost to patient (12\% to 20\%) and the management of the partial loss of a restoration (57\% to $70 \%$ ) as indications for repairs. In contrast, there was a significant change in viewing secondary caries as an indication for repair (46\% to 29\%). In addition, there was a significant, worrisome shift in relation to the use of bonding systems and finishing instruments, together with a reduction in the anticipated longevity of composite repairs.

Conclusion: Aspects of VDPs' attitudes to the repair of DCRs were found to change significantly during the VT year. Not all aspects of the changes observed were considered to be positive. Knowledge and understanding of repairs to DCRs need to be strengthened.

\section{INTRODUCTION}

Vocational training (VT) was devised as a method of providing a structured introduction to general dental practice to newly qualified dentists who wanted to become principals or associates in general dental practice under National Health Service (NHS) regulations. Since October 1993, it has been a requirement for UKtrained dentists to do one year of VT in approved general dental 'training' practices, to be eligible to be al dental list numbers by health authorities. In addition to practice-based training by selected general dental practitioners (GDPs) who are seen as having 'best practice' standards, vocational dental practitioners (VDPs) spend a minimum of 30 postgraduate training days at regional training centres. Most graduates commence VT in July/August of the year they qualify.

Recent national ${ }^{1}$ and international ${ }^{2-4}$ surveys have shown that newly qualified dental graduates can repair DCRs that are failing or have suffered some deterioration e.g. marginal fractures. This indicates familiarity with minimal interventive dentistry, and the repair of a restoration as a favourable alternative to total replacement, assuming the repaired restoration satisfies clinical requirements. The advantages of composite repair, ie partial replacement of a DCR allowing preservation of that portion of the DCR which presents no clinical or radiographic evidence of failure, as an alternative to restoration replacement, are considerable. Unlike repeated restoration replacement, which leads to an acceleration of the restorative cycle ${ }^{5,6}$ with the associated detrimental consequences, including: weakening of the tooth through the loss of tooth substance and repeated insults to the pulp with the increased risk of pulp death, the repair of DCRs does not lead to an acceleration of the restorative cycle and its sequellae.

When newly qualified dentists enter general dental practice, typically to undertake VT, they may be confronted with many dilemmas, resulting from tensions between techniques taught in dental school and the reality of working in the NHS under existing General Dental Services (GDS) arrangements. ${ }^{1}$ Having been taught the merits and procedures for the repair of DCRs, the VDP might be discouraged from practicing such conservative approaches in the management of failing DCRs as a consequence of NHS regulations and fee structures.

The aim of this study was to survey VDPs in England at the beginning and end of a VT year (2002-2003) 
regarding their views on the repair of DCRs and to detect any changes in their views during the VT year.

\section{MATERIALS AND METHODS}

A questionnaire-based cohort study was conducted of VDPs ( $n=560)$ who started VT in England in the summer of 2002. The survey questionnaires (copies available from the corresponding author) were based on those developed by Blum et al. ${ }^{1}$ and used in previous surveys. ${ }^{1,2,4}$ The first questionnaire comprised 16 questions set out on two sides of A4 paper. The questions were asked in a closed-ended format in standard English, making them easy to answer, score and code for analysis by computer. The questionnaire took no longer than three minutes to complete.

The Committee for Vocational Training provided the names and addresses of the Postgraduate Deans for dentistry and of regional VT advisors in England. The initial questionnaire was sent to the 12 Postgraduate Dental Deans in England during September 2002, with a request that it be circulated to their VDPs for completion, collection and return. The questionnaire sought information on the VDPs' place and year of qualification and their views on the repair of DCRs, including indications and details of operative techniques, expected longevity of repaired DCRs and the acceptance of composite repairs by patients.

The follow-up questionnaire was sent to the Deans near the end of the VT year during May 2003, requesting repeated circulation, completion and return of questionnaires. This questionnaire sought similar data to that obtained by the initial questionnaire, together with questions on experience of repairing DCRs during VT. Where the response rate from a deanery was less than $70 \%$, four weeks after sending out the initial or follow-up questionnaire, a copy of the questionnaire together with an explanatory letter was sent to the deaneries' regional VT advisors to encourage further responses. Data collection terminated on 30 June 2003 and the information was collated using the SPSS for Windows statistical package. The views expressed by the VDPs in both tests were compared and analysed. Where the data were categorical, Chi-square values were calculated comparing the proportion of responses in each category on the two occasions. For continuous variables t-tests was used to compare means. All statistical tests were carried out at the 0.05 level of significance.

\section{RESULTS}

Two deaneries chose not to participate in this survey by not returning the questionnaires sent at the beginning and end of the VT year. The findings were therefore based on responses of VDPs from ten deaneries $(n=467)$. The participating deaneries are shown in Figure 1. Three hundred and six VDPs replied in September 2002 and 313 VDPs replied in May 2003, giving response rates of $66 \%$ and $67 \%$ respectively. The questionnaires returned by the participating deaneries included responses to all of the questions. The majority of responding VDPs were found to have qualified in the UK between 2001 and 2002, while those who had qualified abroad and before 2001 were only $3 \%$ and $2 \%$ respectively. From the first questionnaire, it was found that 177 (57\%) of respondents had been taught repair as an alternative to restoration replacement and, more importantly, 222 $(72 \%)$ respondents reported having performed a composite repair at dental school. From the followup questionnaire, it was found that $242(78 \%)$ of the cohort reported having repaired composite restorations during VT, of whom $240(97 \%)$ reported that such treatment had been successful.

The reasons stated by the VDPs for the repair of DCRs, including both general and tooth-related factors, are shown in Figures 2 and 3 respectively. Significant changes in the attitudes of the VDPs during the VT year included a shift to viewing reduction in treatment time [30\% to $48 \%(p<0.001)$ ], cost to patient $[12 \%$ to $20 \%$ $(\mathrm{p}<0.01)]$ and the management of the partial loss of a restoration [57\% to $70 \%(\mathrm{p}<0.01)]$ as indications for repairs. In contrast, there was a significant reduction in viewing secondary caries as an indication for repair [46\% to $29 \%(\mathrm{p}<0.001)]$.

The respondents' reported using mechanical procedures and chemical surface treatments for the repair of direct composite restorations as detailed in Figures 4 and 5 respectively. The data revealed a significant reduction in the use of diamond finishing instruments [76\% to $58 \%(p<0.001)$ ], acid etching $[71 \%$ to $62 \%$ $(\mathrm{p}<0.05)]$ and bonding systems [74\% to $61 \%(\mathrm{p}<0.001)]$ over the VT year. The findings of the initial and followup questionnaire revealed that patients' willingness to accept such repairs was more than 90\%.

The estimated longevity of composite repairs was reported at the start of VT to be, on average, 46 months (S.D., 23 months). At the end of the VT year the expected mean was 36 months (S.D., 23 months). This difference was statistically significant $(t=4.94, p<0.001)$.

\section{DISCUSSION}

The aim of VT is to enhance clinical and administrative competence and to promote high ethical standards and quality of care for patients. ${ }^{7}$ It has been suggested that VT has a positive effect on VDPs, enhancing their preparation for their future responsibilities and career development. 8

There have been a small number of published reports on the changing views and perspectives of VDPs, albeit in relation to gained clinical confidence, ${ }^{9,10}$ and reasons for placement and replacement of restorations ${ }^{11}$ during VT.

The purpose of this survey was to investigate aspects of the changes, if any, in VDPs' views on repairing DCRs during the VT year 2002-2003. However, these types of surveys have inherent limitations, which have been the subject of various correspondence. ${ }^{12-14}$ Whereas such limitations may include possible criticisms of the questionnaire and surveying method, they must be viewed against the need to obtain clinically relevant information based on an insight into the "real-world" of everyday clinical practice. In addition, such surveys serve an important purpose to those responsible for ensuring that teaching and training is in line with current concepts in dentistry. While the data collected provides information on the indications, materials, and techniques used in relation to the repair of DCRs during 
VT, it gives only limited insight into the extent of VDPs' experience with DCR repairs. From the various responses and comments it would appear, however, that the VDPs found it appropriate and gained considerable clinical experience of repairing failing DCRs.

The overall response rate of $66.5 \%$ is similar to response rates in previous surveys of VDPs. ${ }^{9,15}$ Given that two-thirds of the 2002-2003 VDPs in the surveyed deaneries participated in this survey, it is suggested that the findings provide important insight into the changing views of the VDPs, over the selected period, in relation to the repair of failing DCRs. Time and opportunity permitting, it would have been of considerable interest to have surveyed the views of the VDPs' trainers on the repair of failing DCRs. To date, there is limited information available on the acceptance of repairing DCRs among established practitioners. ${ }^{16}$

The data collected indicate that reduction in treatment time and cost to the patient might play a significant role in favour of composite repairs. This finding is of interest given that VDPs are intended to supplement their skills and develop an understanding of patient care in general dental practice free of the widely recognised financial and time pressures inherent in the GDS remuneration system. Importantly, however, the VDPs might have been encouraged by their trainers to be aware of the financial implications of treatment alternatives and as to what procedures are in the best interests of patients.

The finding that VDPs became less inclined to repair DCRs considered to be failing in the presence of secondary caries, might suggest increased caution or increased reluctance to spend time to fully assess failing DCRs or, alternatively, increased awareness of the benefit of monitoring secondary caries in conjunction with diet modification and oral hygiene instruction given to the patient. Secondary caries is the most common reason for the need to replace DCRs; ${ }^{17}$ however, from the work of, for example, Mjör and Toffenetti ${ }^{18}$ it is apparent that secondary caries is frequently misdiagnosed and, when present, typically takes the form of a new primary lesion of caries adjacent to an existing restoration which, as a consequence, may not require replacement. Trends to replacement following the clinical diagnosis of secondary caries, as would appear to be the case in the present study, are regrettable at a time when strenuous efforts and arrangements are being made to promote minimally invasive dentistry, including repair as a viable alternative to the replacement of restorations susceptible to failure. The management of secondary caries is an aspect of everyday clinical practice which warrants further detailed research in the interests of saving patients' tooth tissues, extending the life expectancy of existing restorations and, as a consequence, limiting the massive cost of restoration replacement as a substantial element of everyday oral healthcare maintenance.

Regarding the teaching of repairs to DCRs, it is disappointing to note that only 57\% of the VDPs surveyed indicated that this had been included in their undergraduate programme. This finding is contrary to the findings of a recent survey by Blum et al. ${ }^{1}$ which

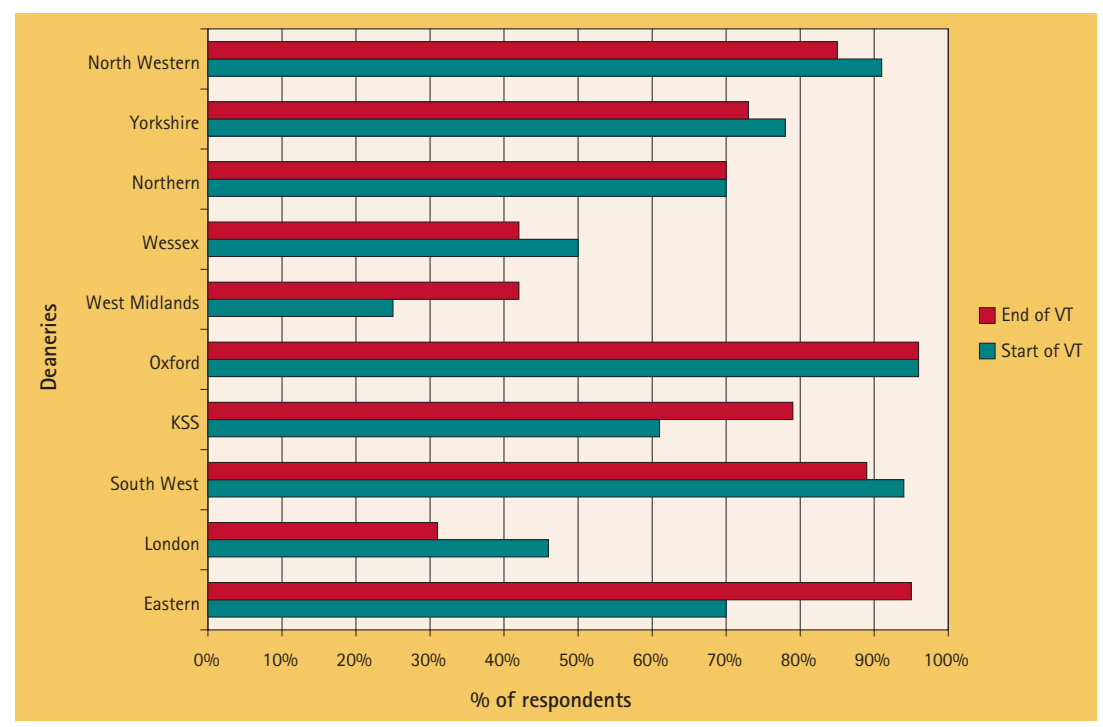

Fig. 1 Details of VDP response rates for the participating deaneries

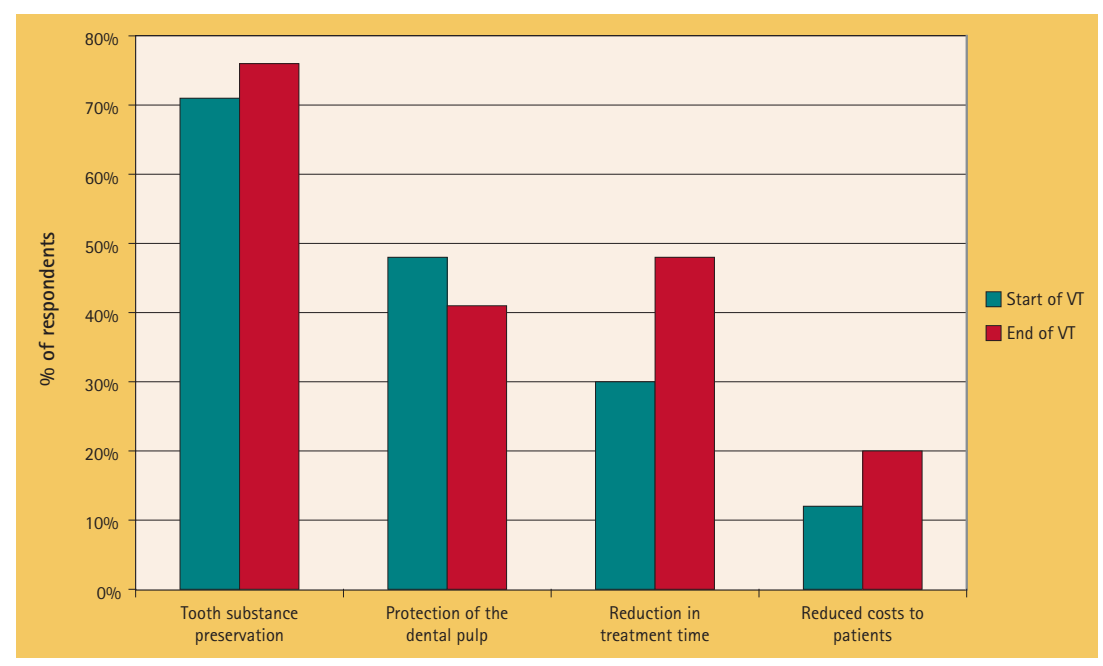

Fig. 2 Summary of the general indications reported for performing direct composite repairs

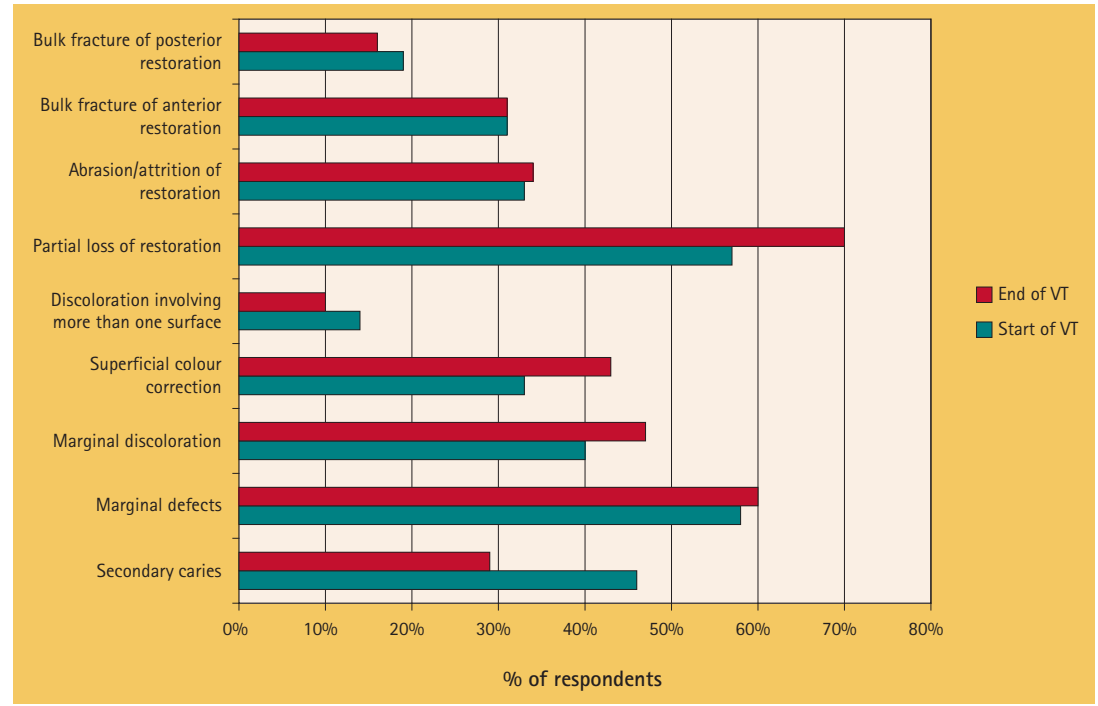

Fig. 3 Summary of the findings in respect of indications for direct composite repair

indicated that recent graduates from all dental schools in the UK and Ireland have received instruction in the repair of direct restorations. However, it is encouraging that $72 \%$ of the respondents indicated that they had performed a composite repair at dental school. 


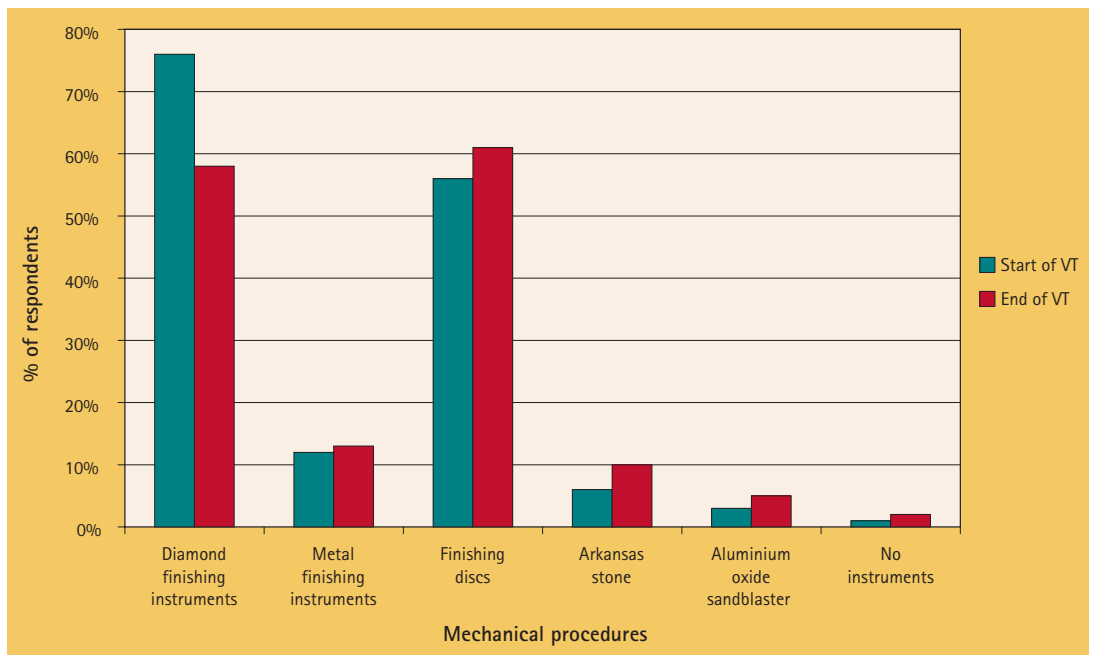

Fig. 4 Summary of the findings pertaining to the mechanical surface treatment on the remaining composite substrate

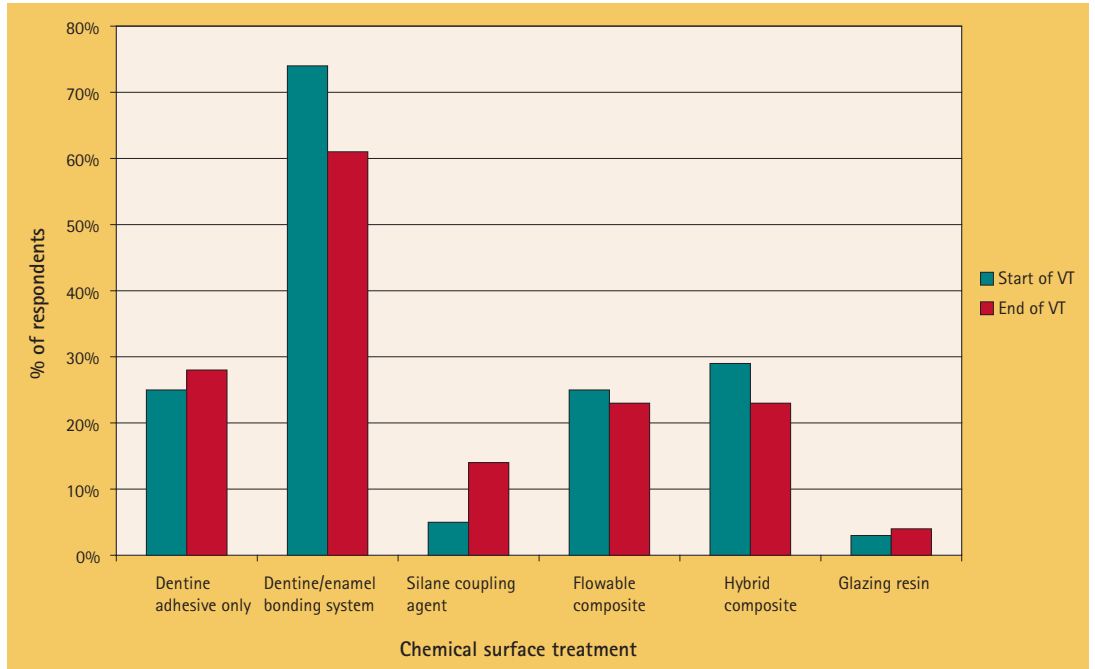

Fig. 5 Summary of the findings pertaining to the surface treatment of the repair substrate

Of great concern, and quite contrary to teaching in dental schools, not all of the surveyed VDPs at the onset of VT considered it appropriate to include etching and bonding in the procedures to effect repairs to DCRs. All the more worrying was the apparent trend to shift away from etching and bonding in the repair of DCRs during the VT year. Etching and bonding is long established as an essential and critical element of all operative procedures for resin composite placement. The apparent omission of etching and bonding by a significant minority of the VDPs surveyed, albeit in procedures for the repair of DCRs, is indefensible as this results in inadequate bond strengths and compromised pulpal protection. VDPs are trained in techniques assessed as having "best practice" standards. To add to this worrisome problem it was of concern to note trends away from what are generally considered to be "best practice" finishing procedures, including the use of diamond finishing instruments.

Notwithstanding the above, the overall willingness of the surveyed VDPs to perform repairs to failing DCRs, and the willingness of the VDPs' patients to accept repairs as an alternative to restoration replacement offers a glimmer of hope of a shift towards minimally invasive dentistry in everyday clinical practice. Anticipated changes to the GDS remuneration system in 2005 will hopefully accelerate this shift. With such change, there will be new needs for robust evidence-based research and continuing professional development in the field of minimally invasive dentistry, but the investment necessary to meet such needs will quickly be recouped and go on to reap countless benefits to patients.

In conclusion, this study lends support to the observation that VDPs' views on aspects of clinical dentistry may change in the VT year, which in the present investigation, were in respect of repairs to DCRs. Not all aspects of the changes observed were positive. Knowledge and understanding of repairs to DCRs needs to be strengthened.

The authors wish to thank the participating vocational dental practitioners for their time in completing the questionnaires. The project could not have been done without their help. The authors would also wish to acknowledge the support of the participating Postgraduate Dental Deans and Regional Advisors in vocational training that assisted in the distribution, collection and return of the questionnaires.

1. Blum IR, Schriever A, Heidemann D et al. Repair versus replacement of defective direct composite restorations in teaching programmes in UK and Irish dental schools. Eur J Prosthodont Rest Dent2002; 10: $151-5$

2. Blum I R, Schriever A, Heidemann D, et al. The repair of direct composite restorations: an international survey of the teaching of operative techniques and materials. Eur J Dent Educ 2003; 7: 41-8

3. Blum I R, Mjör I A, Schriever A, et al. Defective direct composite restorations - replace or repair? A survey of teaching in Scandinavian dental schools. Swed Dent J 2003; 27: 99-104

4. Gordan VV, Mjör I A, Blum I R, et al. Teaching students the repair of resin-based composite restorations: A survey of North American Dental Schools. JAm Dent Assoc 2003; 134: 317-23

5. Gordan VV. In vitro evaluation of margins of replaced resin-based composite restorations. J Esthet Dent 2000; 12: 209-215

6. Gordan VV. Clinical evaluation of class V resin based composite restorations. J Dent 2001; 29: 485-88

7. CVT. Aims and Objectives for Vocational Training 2000. http://eastman.ucl.ac.uk/ shall/whatsvt2.html.

8. Prescott L, Hurst Y, Rennie J S. Comprehensive validation of competencies for dental vocational training and general professional training. Eur J Dent Educ 2003; 7: 154-59

9. Ralph JP, Mercer PE, Bailey H. A comparison of the experiences of newly qualified dentists and vocational dental practitioners during their first year of general dental practice. Br Dent J2000; 189: $101-6$

10. Bartlett D W, Coward PY, Wilson R, et al. Experiences and perceptions of vocational training reported by the 1999 cohort of vocational dental practitioners and their trainers in England and Wales. Br Dent J 2001; 191: 265-70

11. Burke F J T, Cheung S W, Mjör I A, et al. Restoration longevity and analysis of reasons for the placement and replacement of restorations provided by vocational dental practitioners and their trainers in the United Kingdom. Quintessence Int 1999; 30: 234-41

12. Swift EJ, Bader J D, Shugars D A. Glass-ionomer cement restorations and secondary caries: A preliminary report [letter]. Quintessence Int 1996; 27: 581

13. Forsten L. Glass-ionomer cement restorations and secondary caries: A preliminary report [letter]. Quintessence Int. 1996; 27: 791

14. Mount $\mathrm{G} J$. Another letter on glass-ionomer cement restorations. [letter]. Quintessence Int 1996; 27: 582

15. Underwood B, Fox K, Nixon PJ. Alcohol and drug use among vocational dental practitioners. Br Dent J 2003; 195: 265-68

16. Blum I R, Schriever A, Heidemann D, et al. The repair of defective direct composite restorations in dental practice. J Dent Res 2003 82: (Spec/ssue C) C-525, Abstract 372

17. Deligeorgi $V$, Wilson N H F, Fouzas $D$, et al. Reasons for placement and replacement of restorations in student clinics in Manchester and Athens. Eur J Dent Educ 2000: 4: 153-9

18. Mjör I A., Toffenetti F. Secondary caries: a literature review with case reports. Quintessence Int 2000; 31: 165-79 